\title{
Simulation on metro railway induced vibration. Part I: effect of out-of-round wheels
}

\author{
Hougui Zhang ${ }^{1}$, Zhou Ren ${ }^{2}$, Huijuan Zhang ${ }^{3}$, Qiang Liu ${ }^{4}$ \\ 1,3,4Beijing Municipal Institute of Labour Protection, Beijing, 100054, China \\ ${ }^{2}$ Beijing Jiaotong University, Beijing, 100044, China \\ ${ }^{1}$ Corresponding author \\ E-mail:108115261@bjtu.edu.cn, ${ }^{2} 13130708 @ b j t u . e d u . c n,{ }^{3}$ shuiyincy123@163.com, \\ ${ }^{4}$ liuqiang3470@126.com
}

Received 1 November 2019; accepted 7 November 2019 DOI https://doi.org/10.21595/vp.2019.21153

Check for updates

Copyright $(\mathrm{C} 2019$ Hougui Zhang, et al. This is an open access article distributed under the Creative Commons Attribution License, which permits unrestricted use, distribution, and reproduction in any medium, provided the original work is properly cited.

\begin{abstract}
This paper discussed the effect of out-of-round wheels on simulation of rail dynamic behavior in the frequency range for ground vibration and ground-borne noise. A train-track interaction model was built by software Simpack and Abaqus. The input roughness was measured from a worn wheel and was applied moving on perfect smooth rail surface in different train speeds. Simulation results indicated that out-of-round wheel would affect the calculation result that could not be neglected, as the affected frequency range would be lower enough to influence the ground vibration (1-80 Hz) and ground-borne noise (16-250 Hz).
\end{abstract}

Keywords: railway induced vibration, out-of-round wheels, and acoustic roughness.

\section{Introduction}

Ground vibration from trains is an increasingly important environmental issue. It manifests itself in two ways: low frequency vibration in the range $1-80 \mathrm{~Hz}$ is perceived by line side residents as whole-body feel able vibration, whereas higher frequency vibration in the range $16-250 \mathrm{~Hz}$ is radiated as sound inside buildings and is known as ground-borne noise [1,2].

During the last decades, many different theoretical models are available to simulate the dynamic behavior of railway tracks, which plays an important role on the generation of vibration and rolling noise [3-5]. In these models, Hertz wheel/rail contact model was common used and irregularities between wheel-rail were considered as the excitation element. However, a great difficulty in practice is to find appropriate values for irregularities despite them are so important that cannot be ignored. when calculate the structures subjected the moving loads from railway trains, it would be sufficient using irregularities which was simplify generated from functions of power spectrum density (PSD) summarized from US or Germany railway main lines. But a more comprehensive understanding of the rolling noise and vibration excitation mechanism now requires the irregularities to be defined in high frequency range [6]. The deterioration of the running surface, such as corrugated rail and out-of-round wheels, was defined as 'acoustic roughness' which was associated with high frequency vibration and rolling noise induced by railway system.

In order to direct the maintenance strategy of acoustic rail grinding and wheel re-profile, it is necessary to establish a relationship between rail dynamic behavior and deterioration of the running surface. This paper described the simulation model briefly and calculated the rail dynamic behavior in high frequency range, considering the effect of out-of-round wheels moving on perfect smooth rail surface in different train speeds. A subsequent paper would take the effect of corrugated rail into consideration.

\section{Measurement of out-of-round wheel}

Wheel irregularities were measured using Calipri Prime (Fig. 1), which uses laser light section technology, so a camera/laser unit in the measurement device records the flange profile of the 
wheels without having to manually attach it to the wheel profile.

Measurement was conducted in rolling stock maintenance yard. The redial/axial run-out data was captured from 48 worn out wheels and diameter difference was summarized as the surface irregularities (Fig. 2) and 1/3 octave wavelength spectrum was shown in Fig. 3.
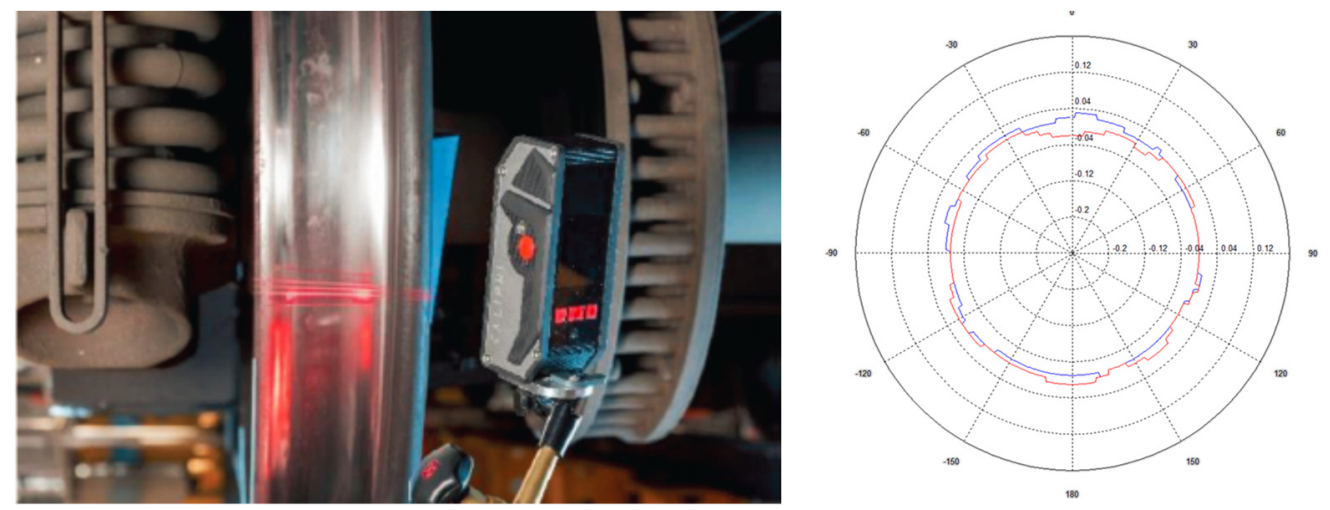

Fig. 1. Out of round measurement

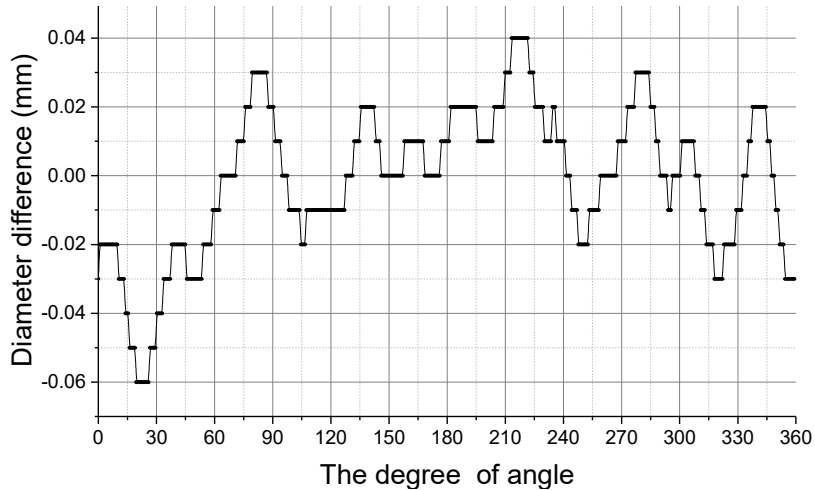

Fig. 2. Surface irregularities of wheel profile

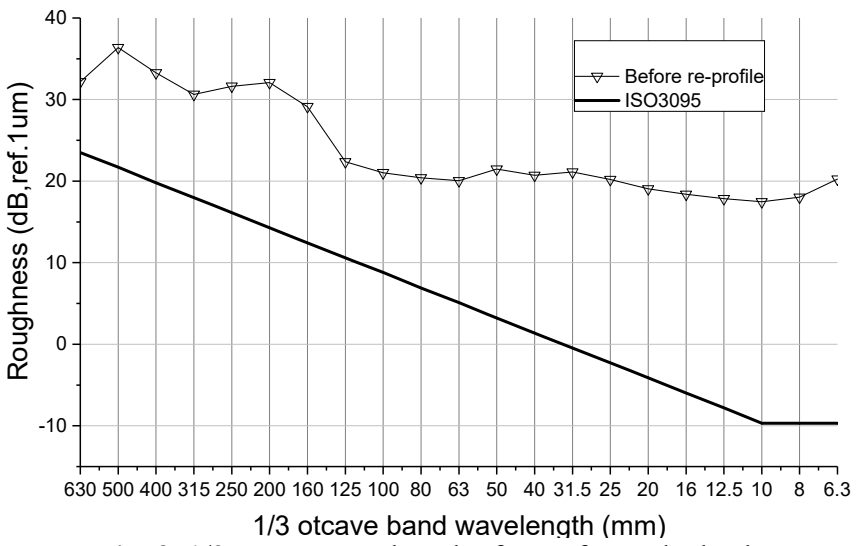

Fig. 3. 1/3 octave wavelength of out-of-round wheel

\section{Train-track interaction model}

The train-track interaction model was built by software Simpack and Abaqus. Basic input data was shown in Table 1. 
In the simulation model, the vehicle part was considered as a dynamics of Multi-body system. A model of common used metro train in Beijing was therefore built using the wheel/rail module of SIMPACK software.
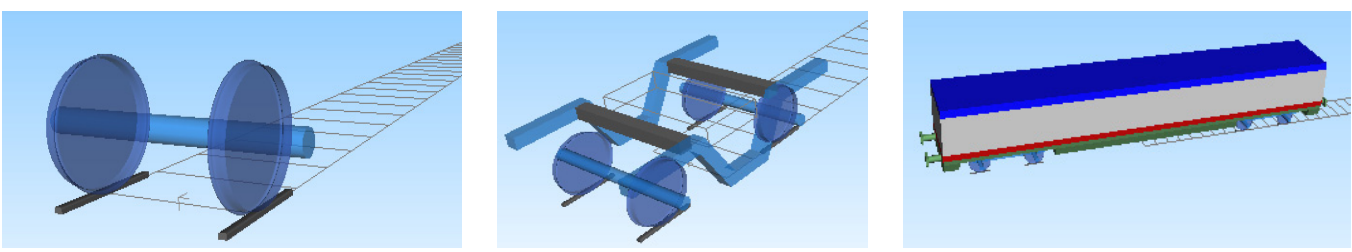

Fig. 4. Vehicle model using SIMPACK software

In the simulation model, the track part was considered its elastic behavior. The finite element model was built for a common used DTVI2 track system in Beijing using ABAQUS software.

The wheel-rail contact adopt SIMPACK default model (Fig. 6), using Hertz contact ellipse and simplified no-linear theory (J. J. Kalker).

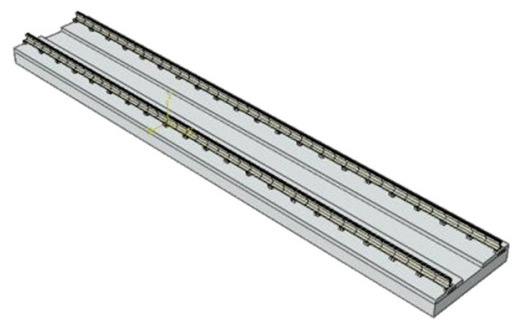

Fig. 5. Finite element track model using ABAQUS software

Table 1. The input data for simulation

\begin{tabular}{|c|c|c|}
\hline Item & Value & unit \\
\hline Length of train & 12.6 & $\mathrm{~m}$ \\
\hline Length of bogie & 2.3 & $\mathrm{~m}$ \\
\hline Mass of train & 43000 & $\mathrm{~kg}$ \\
\hline Mass of bogie & 3600 & $\mathrm{~kg}$ \\
\hline Mass of wheel-set & 1700 & $\mathrm{~kg}$ \\
\hline Diameter of wheel & 840 & $\mathrm{~mm}$ \\
\hline Type of rail & $\mathrm{GB} 60$ & \\
\hline Stiffness of fastening system & 20 & $\mathrm{kN} / \mathrm{mm}$ \\
\hline
\end{tabular}

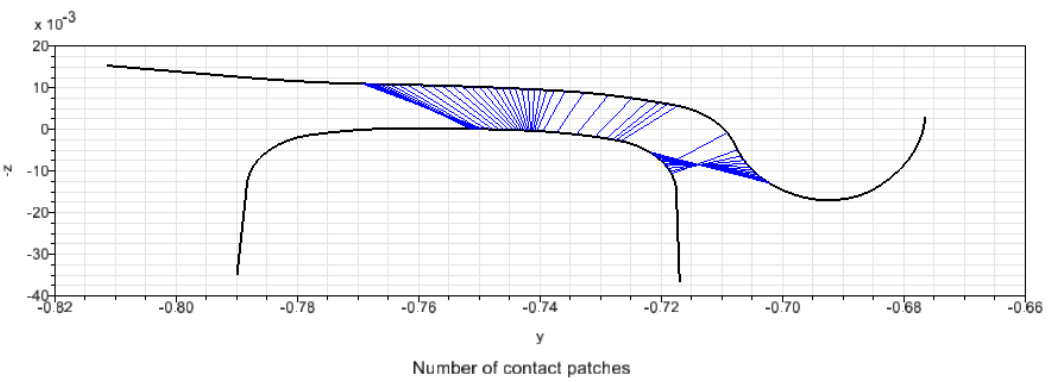

Fig. 6. Wheel-rail contact

\section{Calculation result}

In order to keep as much wavelength information as possible, unprocessed raw data would be better used to indicate the contribution of out-of-round wheel on the train induced vibration 
simulation. Therefore, although the acoustic roughness of 48 wheels were measured before and after re-profile, comparison was still carried out between one worn wheel selected in random and a perfect round default wheel from SIMPACK software.

\subsection{Time history and frequency spectrum}

Typical calculation results were focused on the rail vibration velocity as which was already found close related to pass-by rolling noise. In this paper, time history and frequency spectrum were shown in Fig. 7 and Fig. 8.

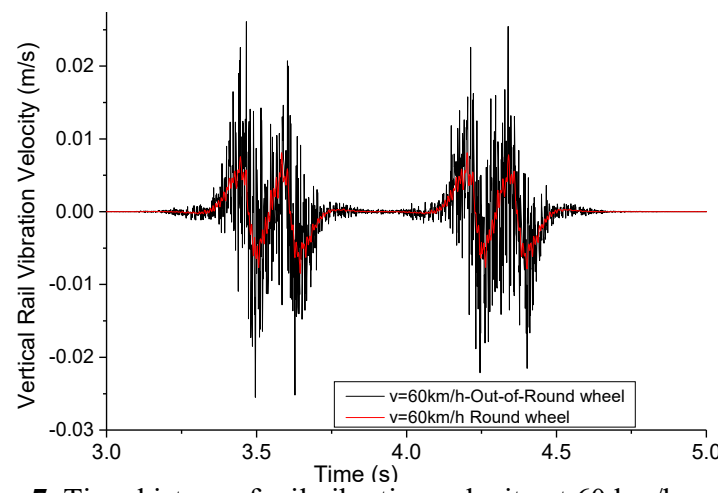

Fig. 7. Time history of rail vibration velocity at $60 \mathrm{~km} / \mathrm{h}$ speed

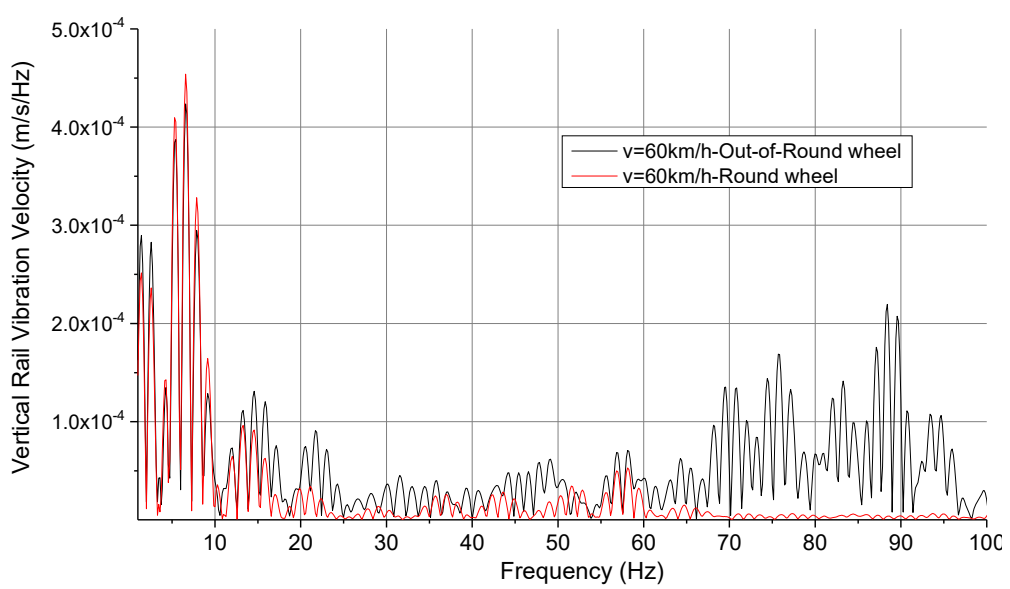

Fig. 8. Frequency spectrum of rail vibration velocity at $60 \mathrm{~km} / \mathrm{h}$ speed

From Fig. 7 two bogies with four wheels were clearly distinguished in the pass-by time history. The dynamic response of rail was obviously different for the worn wheels and the perfect round wheels. It is clear that the out-of-round wheel resulted in stronger rail vibration. After FFT analysis, the frequency spectrum (See Fig. 8) was indicated that the vibration were not effected in low frequency range $(<12.5 \mathrm{~Hz})$ while dramatic stronger vibration occurs in higher frequency range $(>12.5 \mathrm{~Hz})$.

\subsection{Effect of train speed}

Further calculations were conducted in different cases, considering the train moving at $60 \mathrm{~km} / \mathrm{h}, 90 \mathrm{~km} / \mathrm{h}$ and $120 \mathrm{~km} / \mathrm{h} .1 / 3$ octave band vibration response were recorded and analyzed in Fig. 9. 

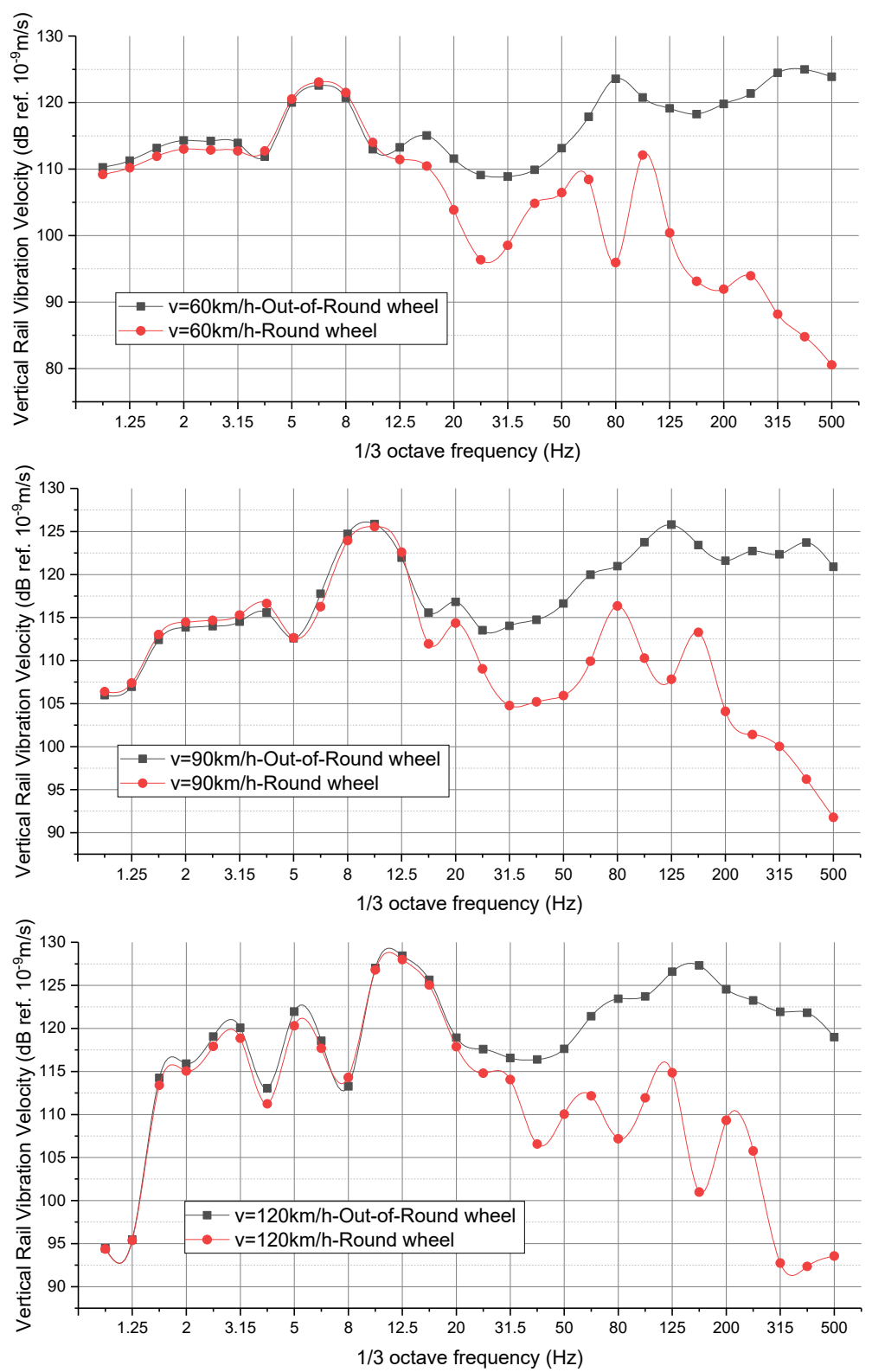

Fig. 9. 1/3 octave band vibration for different train speeds

From Fig. 9, it indicated that:

1) The out-of-round wheel had an obvious effect on the simulation result in higher frequency range;

2) The pass-by rail vibration velocity showed a similar phenomenon, that there is a minimal affected frequency, from which the simulation result was seams not influenced by out-of- round wheels.

3) When considering the relationship between train speed and the typical frequency (Eq. (1)), the minimal affected frequency was related to the wavelength at 0.5 time of wheel circumference: 
$\lambda=\frac{V}{f}=\frac{60 \mathrm{~km} / \mathrm{h}}{12.5 \mathrm{~Hz}}=\frac{120 \mathrm{~km} / \mathrm{h}}{25 \mathrm{~Hz}} \cong \frac{\frac{90 \mathrm{~km}}{h}}{18 \mathrm{~Hz}} \cong \frac{\pi D}{2}$.

\section{Conclusions}

Based on the above presented simulation results, interesting findings could be summarized as following:

1) In simulations model on train induced vibration, out-of-round wheel would affect the calculation result that could not be neglected, as the affected frequency range would be lower enough to influence the ground vibration $(1-80 \mathrm{~Hz})$ and ground-borne noise $(16-250 \mathrm{~Hz})$.

2) The minimal affected frequency was related to the wavelength, and which value approximately equal to half of the wheel circumference.

\section{Acknowledgements}

This work was under the support of Beijing Natural Science Foundation (No. 3184047), Beijing Academy of Science and Technology Funds (No. OTP-2018-002) and Beijing Public Finance innovation project in 2018 (PXM2018-178304_000007).

\section{References}

[1] Thompson D. J. Railway Noise and Vibration: Mechanisms, Modelling and Means of Control. Elsevier, Oxford, 2008.

[2] Lombaert G., Degrande G., François S., Thompson D. J. Ground-borne vibration due to railway traffic: a review of excitation mechanisms, prediction methods and mitigation measures. Notes on Numerical Fluid Mechanics and Multi-disciplinary Design, Vol. 126, 2015, p. 253-287.

[3] Jiang B. L., Ma M., Li M. H., et al. Experimental study of vibration characteristics of floating slab track in metro turnout zones. Proceedings of the Institution of Mechanical Engineers, Part F - Journal of Rail and Rapid Transit, Vol. 233, Issue 10, 2019, p. 1081-1096.

[4] Ma M., Liu W. N., Qian C. Y., et al. Study of the train-induced vibration impact on a historic Bell Tower above two spatial overlapping metro lines. Soil Dynamics and Earthquake Engineering, Vol. 81, 2016, p. 58-74.

[5] Ma M., Valéri Markine, Liu W. N., et al. Metro train-induced vibrations on historic buildings in Chengdu, China. Journal of Zhejiang University - Science A: Applied Physics and Engineering, Vol. 12, Issue 10, 2011, p. 782-793.

[6] BS EN ISO3095:2005 Railway applications - Acoustics - Measurement of Noise Emitted by Railbound Vehicles, 2005. 